Аннотация: В статье рассматривается роль и место темы словообразования в системе курса РКИ, значение темы, трудности ее усвоения и некоторые особенности функционально-коммуникативного подхода к представлению темы в иностранной аудитории.

Ключевые слова: словообразовательная модель, производные слова, объект исследования, единица отбора материала, этапы представления темы, пути организации материала, функционально-коммуникативный подход

V.V. Dobrovolskaya (Moscow, Russia)

\title{
Word Formation in the System of Russian as a Foreign Language
}

Abstract: The article discusses the role and place of the theme of word formation in the system of the course of Russian as a Foreign Language, the meaning of the topic, the difficulties of its mastering and some features of the functional-communicative approach to the presentation of the topic to the foreign audience.

Key words: derivational model, derived words, object of study, a unit of the material's selection, the phases of the theme presentation, the paths of organizing material, functional and communicative approach

Словообразование - это раздел языкознания, который изучает словообразовательные средства и законы образования и системной организации производных и сложных слов, а также закономерности функционирования производных и сложных слов в текстах разной коммуникативной направленности.

Словообразование в системе РКИ представляет собой описание словообразовательных моделей, на которых строятся ряды производных слов, и изучение закономерностей функционирования словообразовательных аффиксов в слове, а также функционирование производных и сложных слов в предложении, обусловленное коммуникативными и когнитивными задачами говорящего. При этом основным объектом исследования являются производные слова, которые реально представлены в речевой деятельности, а основной единицей обучения русскому словообразованию выступает словообразовательная модель, которая является единицей отбора учебного материала для занятий по РКИ, а также базовой единицей словообразова- 
тельного анализа и синтеза. На базе словообразовательных моделей формируется представление иностранных учащихся о схемах построения производных и сложных русских слов, о русских аффиксах и их значении.

Основной единицей описания семантической стороны русского словообразования являются семантико-смысловые категории (значение действия, деятеля, признака, качества и др.), которые в совокупности представляют собой словообразовательный фрагмент языковой картины мира.

В целом словообразовательная система русского языка включает в себя элементы, из которых состоят значимые единицы слова: корневые морфемы и служебные морфемы (префиксы, суффиксы, интерфиксы и постфиксы), - и определяет роль этих единиц в словопроизводстве. В систему входят также производные и непроизводные слова, законы, по которым производные слова мотивируются непроизводными, способы образования слов и словообразовательные модели.

Значение темы словообразования в системе изучения русского языка достаточно велико. Система представления русского словообразования в курсе РКИ выявляет связь производных слов с лексикой, морфологией, синтаксисом, стилистикой и лингвистикой текста, что в целом позволяет представить динамичную модель функционирования языка.

В лексике рассматриваемая тема способствует расширению активного, пассивного и потенциального словаря учащихся за счет осознания и использования словообразовательных моделей, способствует развитию у учащихся языковой догадки, созданию представления о языке как о развивающейся системе, пониманию норм словоупотребления, развитию интереса к слову как единице языка.

В грамматике тема словообразования дает четкое представление о структуре слова и, следовательно, о закономерностях его изменения, закрепляет знание предложного и беспредложного управления, помогает усвоить категорию слова, направляет законы глагольного управления и синтаксической сочетаемости, помогает понять структуру русского предложения и конкретизирует многие грамматические правила (например, правила синонимических замен).

В области работы с текстом она обеспечивает беспереводное понимание сложного текста, являясь инструментом для чтения, на котором базируется смысловой словообразовательный анализ и языковая догадка, необходимые при чтении художественного текста и аутентичного текста по специальности учащихся. К тому же словообразование является одним из источников терминологической лексики в области специальности, служит ориентиром для определения значения новых слов по их грамматической форме, раскрывает значение сложных слов и помогает анализу и составлению словообразовательной цепочки и словообразовательной парадигмы.

Что касается отношения словообразования с видами речевой деятельности, то в чтении и аудировании мы учим осознанному отличению производного слова от непроизводного, пониманию структуры словообразовательной модели, ее мотивирующей основы и аффиксов и осознанию на этой базе структуры и значения нового незнакомого слова. При этом у учащихся формируется навык определения значения слова по его формальным показателям.

В говорении и письме иной речи мы учим отталкиваться от слова, которое выступает в роли производящего, и выбирать необходимый формант, который можно присоединить к данной основе, опираясь на словообразовательные модели, отработанные на занятиях. В письменной речи изучение словообразования способствует 
также орфографической грамотности учащихся, поскольку морфологический принцип русского правописания требует одинаково писать любую часть слова независимо от их произношения.

Русский язык отличается богатством словообразовательной системы, большим разнообразием аффиксальных форм, разнообразием способов словосложения и словосокращения. Число производных слов в системе русского языка преобладает, на одно непроизводное слово приходится семь производных. Это, разумеется, осложняет отбор материала для курса РКИ и вызывает трудности у иностранных учащихся при изучении темы «Словообразование».

Самыми частотными трудностями, провоцирующими ошибки в речи учащихся, являются:

- незнание аффиксов и их значения и вытекающее из этого непонимание (или неточное понимание) значения производных, сложных и сложносокращённых слов;

- отсутствие навыков стилистической маркировки слов с определенными аффиксами и неправильное употребление их в речи;

- незнание сочетаемости слов с различными аффиксами, делающее невозможным употребление их в процессе коммуникации;

- непонимание текстообразующей роли слова с различными аффиксами, неумение употреблять их при построении текста;

- некорректная расшифровка и составление сложных слов и аббревиатур.

Тема словообразования - сквозная тема пролонгированного курса РКИ. Условно ее изучение можно разделить на три этапа, каждый из которых имеет свои задачи и особенности.

На первом (начальном) этапе учащиеся получают общее представление о составе слова и некоторых словообразовательных морфемах. Это интуитивноимитатитвная стадия усвоения материала на минимальном терминологическом словнике. В этот период имеет место регулярное наблюдение над словообразовательными элементами, проводится рассмотрение наиболее употребительных аффиксов, дается общее понятие о типах именного и глагольного словообразования и группировке словообразовательного материала по семантико-ситуативному принципу. Возможна активизация некоторых четко алгоритмизируемых словообразовательных моделей, накапливается лексика.

На втором (основном) этапе обучения дается представление о способах образования слов различных частей речи, увеличивается запас рецептивного и продуктивного словаря учащихся.

Затем следует изучение аффиксов существительных, прилагательных и глаголов в системе, распределение аффиксов по семантическим группам, изучение сочетаемости производных слов, позволяющее узнавать их в контексте и использовать словообразовательные модели в речи, осознание текстообразующей роли словообразовательных моделей. В целом можно сказать, что основной этап - это достаточно длительный период накопления деривационных моделей и вписывания в них производных слов, за которыми следуют обобщение и систематизация словообразовательных средств русского языка. 
На третьем (завершающем) этапе обучения происходит осознание учащимися системы русского словообразования на основе анализа и синтеза словообразовательных единиц разного плана, изучение многозначности аффиксов и дифференциация однокоренных слов по смыслу в зависимости от использования того или иного аффикса, изучение структуры и роли сложных и сложносокращенных слов, дальнейшее расширение пассивного и потенциального словаря учащихся для понимания текста в чтении и аудировании. Параллельно проводится работа по пополнению активного лексического запаса учащихся путем образования новых слов и морфемного анализа потенциального словаря.

Работа по словообразованию базируется на словообразовательных моделях, репродуктивных и продуктивных упражнениях, активизирующих материал моделей, и текстах, насыщенных производными словами.

Она может проводиться на аспектных занятиях по обучению грамматике (изучение морфологической структуры слова), на аспектных занятиях по лексике (обогащение и активизация словарного запаса учащихся), на комплексных занятиях по чтению и аудированию (анализ текста, включающего производные, сложные и сложносокращенные слова).

Главная задача преподавателя состоит в том, чтобы ознакомить учащихся с основными способами образования слов, со значением аффиксов, с их ролью в слове, показать, как функционируют производные слова в речи, как они участвуют в решении коммуникативных задач обучения, сформировать у учащихся навыки углубленного и точного понимания текста, помочь творческому усвоению языка.

При функциональном подходе к описанию словообразования в целях его преподавания в иностранной аудитории реализуются два направления:

- описание закономерностей функционирования словообразовательного форманта в его формально-семантическом взаимодействии с другими морфемами, особенно с корневой. Основной единицей обучения здесь выступает словообразовательная модель, которая репрезентирует ту или иную словообразовательную категорию;

- изучение функционирования производного слова в предложении, высказывании и тексте для реализации коммуникативных задач обучения. При этом в качестве объекта наблюдения здесь выступает производное слово определенного словообразовательного типа, которое характеризуется базовыми закономерностями функционирования в предложении, высказывании и тексте.

Существуют некоторые специфические особенности методического аспекта представления темы «Словообразование» в курсе РКИ.

Во-первых, материал темы «Словообразование» не всегда подлежит формальному обобщению в ходе занятий. Достаточным обобщением того или иного фрагмента темы может служить четкость и упорядоченность самой презентации материала с учетом его связи с лексикой, грамматикой и информативным материалом курса обучения.

Во-вторых, при прохождении этой темы в целом несколько сдвигается само соотношение понятий актива и пассива. Так, например, сама словообразовательная модель в речи учащихся может оставаться в пассиве, но она активна в том смысле, что, присутствуя в сознании учащихся, обеспечивает понимание текста любой трудности. Говоря иными словами, мы широко используем словообразователь- 
ный анализ и ограничиваем словообразовательный синтез рамками конкретной учебной программы, направляя значительную часть словообразовательного материала в рецептивные виды речевой деятельности.

В-третьих, продвижение в теме «Словообразование» в каждом фрагменте тренировки идет, как правило, в направлении от слова к словосочетанию, а затем к предложению и тексту, показывающему реальное употребление производного слова в речи.

В системе презентации и отработки словообразовательного материала большую роль играет наглядность. Материал представляется в таблицах, снабженных развернутым комментарием, носящим характер правила-инструкции. Нередко таблицы дополняются «Лексикой для справок», из которой преподаватель и учащийся могут выбирать нужный им лексический материал, соотнося его с графами таблицы, представляющей изучаемую модель.

Группировка всего словообразовательного материала в ходе учебного процесса производится на смысловой основе, что дает возможность его органического включения в ткань практического курса РКИ. При этом уделяется внимание конкретным употреблениям производных слов и особенностям коммуникативной установки их речевой реализации. В результате этого происходит отработка и усвоение словообразовательных средств, имеющих то или иное значение.

В заключение еще раз подчеркнем, что с точки зрения коммуникативного подхода к словообразованию при изучении этой темы в центре внимания находится не словообразовательный формант и даже не словообразовательная модель, а производное слово как компонент высказывания и текста. Это слово рассматривается не только как единица, относящаяся к производящей основе и соотносимым с ней словообразовательным формантам, но и как единица текста, в котором она функционирует в речи.

Таким образом, можно сказать, что функционально-коммуникативное описание словообразовательного материала вскрывает механизм образования слов. И в то же время оно направлено на исследование речевых единиц, выражающих интенции коммуникативными словообразовательными средствами. Аффиксы обладают собственным значением и несут в себе определенное когнитивное содержание, которое входит в общее содержание высказывания. Что касается производных слов, то они являются единицами языка, но в то же время их составной характер учитывается коммуникантами в процессе выражения своих интенций. Таким путем словообразовательный материал «вносит свой вклад» в коммуникацию, реализуя и уточняя интенции коммуниканта.

\section{ЛИТ Е РАТ У РА}

1. Амиантова Э.И. К вопросу о функционально и коммуникативно значимом описании словообразования (на материале внутриглагольного префиксального словообразования) // Слово. Грамматика. Речь. Вып. 1. М.: МАКС Пресс, 1999. С. 16-22.

2. Афанасьева И.Н., Дунаева Л.А., Клобукова Л.П., Красильникова Л.В., Яиенко И.И. Лингводидактические аспекты отбора и представления словообразовательного материала в Лексическом минимуме Третьего уровня общего владения русским языком как иностранным // Актуальные проблемы обучения русскому языку как иностранному и русскому языку как неродному / МГОУ. М., 2016. С. 35-41.

3. Белова Н.А. Функциональные словообразовательные средства в контексте изучения общеязыковых функций // Язык. Литература. Культура. Вып. 6. М.: МАКС Пресс, 2010. C. $45-55$. 
4. Добровольская В.В. Роль и место словообразования в курсе системе преподавания РКИ // Слово. Грамматика. Речь. Вып. 17. М.: МАКС Пресс, 2016. С. 230-239.

5. Клобукова Л.П. Об изучении русского словообразования в иностранной аудитории // Русский язык для студентов-иностранцев. Вып. 20. М.: Русский язык, 1981.

6. Красильникова Л.В. Словообразовательный компонент коммуникативной компетенции иностранных учащихся-филологов: на материале суффиксальных существительных. М.: МАКС Пресс, 2011. 360 с.

7. Красильникова Л.В. Методический потенциал единиц системы русского словообразования // Слово. Грамматика. Речь. Вып. 15. М.: МАКС Пресс, 2014. С. 3-13.

8. Красильникова Л.В. Представление словообразовательного материала в программах по русскому языку для учащихся-филологов // Язык. Сознание. Коммуникация. Вып. 60. М.: МАКС Пресс, 2018. С. 140-152.

9. Крючкова Л.С. Словообразование в процессе работы с иностранными учащимися // Язык. Литература. Культура. Вып. 11. М.: МАКС Пресс, 2015.

10. Крючкова Л.С. Словообразование как аспект обучения иностранных учащихся русскому языку // Язык. Литература. Культура. Вып. 12. М., 2017.

11. Крючкова Л.С. Словообразование. Форма, семантика, функция, методика обучения. М.: Флинта, 2019. 216 с.

12. Милославский И.Г. Принципы описания словообразования в грамматике русского языка для иностранцев // РЯЗР. № 6(98). М., 2018 (в печати).

\section{REFERENCES}

1. Amiantova E.I. On the Question of a Functionally and Communicatively Meaningful Description of Word Formation (Based on the Material of the Verbal Prefixal Word Formation). In: Word, Grammar, Discourse. Issue 1. Moscow. MAKS Press Publ. 1999, pp. 16-22.

2. Afanasyeva I.N., Dunaeva I.N., Klobukova L.P., Krasilnikova L.V., Yatsenko I.I. Linguo-Didactic aspects of selection and presentation of word-building material in the Lexical Minimum of the Third Level of General Knowledge of Russian as a Foreign Language. In: Actual Problems of Teaching Russian as a Foreign Language and Russian as a Non-native Language / Moscow State Regional University. Moscow. 2016, pp. 35-41.

3. Belova N.A. Functional Derivational Means in the Context of General Language Functions Study. In: Language. Literature. Culture. Issue 6. Moscow. MAKS Press Publ. 2010, pp. $45-55$.

4. Dobrovilskaya V.D. The Role and Place of Word Formation in the Course of the System of Teaching of Russian as a Foreign Language. In: Word, Grammar, Discourse. Issue 17. Moscow. MAKS Press Publ. 2016, pp. 230-239.

5. Klobukova L.P. On the Study of Russian Word Formation in a Foreign Audience. In: The Russian Language for Foreign Students. Issue 20. Moscow. Russky Yazyk Publ. 1981.

6. Krasilnikova L.V. (2011) The Word-building Component of the Communicative Competence of Foreign Philological Sudents: On the Material of Suffixing Nouns. Moscow. MAKS Press Publ. 360 p.

7. Krasilnikova L.V. Methodical Potential of Units of the Russian Word Formation System. In: Word, Grammar, Discourse. Issue 15. Moscow. MAKS Press Publ. 2014, pp. 3-13.

8. Krasilnikova L.V. Presentation of Word-Formation Materials in the Russian Language Programs for Philology Students // Language - Mind - Communication. Issue 60. Moscow. MAKS Press Publ. 2018, pp. 3-13. 
9. Kruchkova L.S. Word Formation in the Process of Working with Foreign Students. In: Language. Literature. Culture. Issue 11. Moscow. MAKS Press Publ. 2015.

10. Kruchkova L.S. Word Formation as an Aspect of Teaching Foreign Students to the Russian Language. In: Language. Literature. Culture. Issue 12. Moscow. MAKS Press Publ. 2017.

11. Kruchkova L.S. (2019) Word Formation. Form, Semantics, Function, Teaching Methodology. Moscow. Flinta Publ. 216 p.

12. Miloslavsky I.G. Principles of the Description of Word Formation in the Gammar of the Russian Language for Foreigners. Russky Yazyk za Rubezhom. 2018. No 6(98) (in print).

Сведения об авторе:

Валерия Васильевна Добровольская,

доцент

филологический факультет

МГУ имени М.В. Ломоносова
Valeria V. Dobrovolskaya,

Associate Professor

Philological Faculty

Lomonosov Moscow State University 